\title{
Efficiency evaluation of a photovoltaic system simultaneously generating solar electricity and hydrogen for energy storage
}

\author{
S. Abermann ${ }^{1, a}$ \\ ${ }^{1}$ AIT Austrian Institute of Technology GmbH, Energy Department, Giefinggasse 2, 1210 Vienna, \\ Austria
}

\begin{abstract}
The direct combination of a photovoltaic system with an energy storage component appears desirable since it produces and stores electrical energy simultaneously, enabling it to compensate power generation fluctuations and supply sufficient energy during low- or non-irradiation periods. A novel concept based on hydrogenated amorphous silicon (a-Si:H) triple-junction solar cells, as for example a$\mathrm{Si}: \mathrm{H} / \mathrm{a}-\mathrm{SiGe}: \mathrm{H} / \mathrm{a}-\mathrm{SiGe} \mathrm{H}$, and a solar water splitting system integrating a polymer electrolyte membrane (PEM) electrolyser is presented. The thin film layer-by-layer concept allows large-area module fabrication applicable to buildings, and exhibits strong cost-reduction potential as compared to similar concepts. The evaluation shows that it is possible to achieve a sufficient voltage of greater than $1.5 \mathrm{~V}$ for effective water splitting with the a-Si based solar cell. Nevertheless, in the case of grid-connection, the actual energy production cost for hydrogen storage by the proposed system is currently too high.
\end{abstract}

\section{Motivation}

Solar energy has a great potential to cover a big share of the future energy demand due to its global availability and technological progress [1,2]. The 'Achilles' heel' of photovoltaic (PV) energy generation is the yearly and especially the daily variation of solar irradiation resulting in a nonuniform electricity generation. The daily energy production of a 'standard' roof-sized photovoltaic system in northern Europe is schematically shown in Figure 1. The maximum electricity production on a summer day is usually achieved at noon. Nevertheless, the respective average power consumption of a household in this region does not follow this curve (or vice versa), as can be seen in Figure 1.

Accordingly, the direct combination of a PV system with an energy storage component that produces and stores electrical energy simultaneously appears desirable. By that it may be able to compensate power generation fluctuations and supply energy during low- or non-irradiation periods. In this context, excess/deficient PV production can be sold to/bought from the grid, or transferred to a (local) storage system and used in case of insufficient solar energy production.

\footnotetext{
a e-mail : stephan.abermann@ait.ac.at
} 


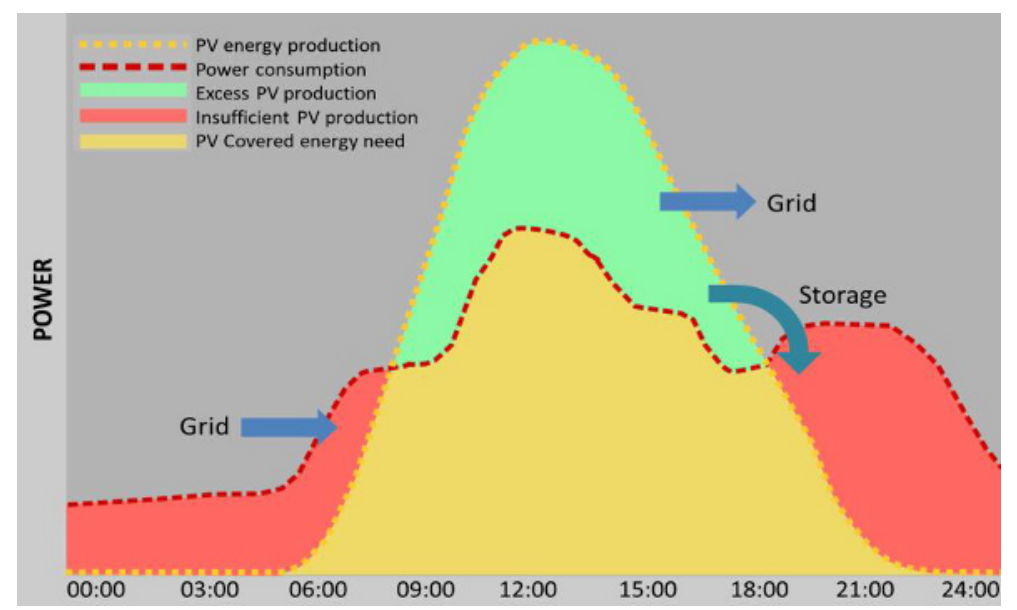

Fig. 1. Daily energy production of a 'standard' roof-sized photovoltaic (PV) system superimposed on the average power consumption of a northern European household on a summer day.

Containing the storage, hydrogen is very interesting, since it can be stored, shipped and combusted without harmful reactants [3]. In addition, it is possible to produce hydrogen by renewable energy sources, such as light-induced water splitting [3,4]. A system simultaneously generating solar electricity and hydrogen may instantaneously deliver and store energy. Recently [5], we presented the concept for a compact PV system based on hydrogenated amorphous silicon thin film solar cells to simultaneously generate solar electricity and hydrogen.

\section{Background}

The solar splitting of water to hydrogen and oxygen driven by photon energy has already been discussed [6,7]. Separating the electrolyte from the solar cell material appears beneficial, especially regarding stability issues [4]. Hereby, the electrodes of the electrochemical cell are either directly connected to the solar cell contacts [8] or form a part of the back contact [9].

It was demonstrated that more than $90 \%$ of PV energy could be converted into hydrogen energy as long as the generated voltage of the solar cell at its maximum power point is considerably larger than the thermodynamic potential for the water splitting reaction $\left(\mathrm{E}^{\circ} \mathrm{H}_{2} \mathrm{O}\left(25^{\circ} \mathrm{C}\right)=1.229 \mathrm{~V}\right)$ and close to the thermo-neutral potential $\left(\mathrm{E}_{\mathrm{tn}}=1.48 \mathrm{~V}\right)[3,6]$. Peharz and co-workers developed a system based on concentrator tandem III-V solar cells and a polymer electrolyte membrane (PEM) electrolyser [3]. This device exhibits independently working solar cell/electrolyser combinations achieving high solar to hydrogen conversion efficiencies of up to $18 \%$. Moreover, the scalable system does not need equipment for coupling the PV array to the electrolyser.

However, mainly due to high manufacturing costs and complexity, III-V tandem cells are not a mass technology yet; and even if applied with concentrator optics they are still not cost-competitive with Si-based PV technologies [1]. In addition, the concentrator optics make the system unfavorable for building integration.

\section{Concept}

The concept we presented is based on amorphous silicon triple-junction solar cells and a solar water splitting system integrating a PEM electrolyser, and may overcome the above given issues (Figure 2). Solar cells based on stacks of hydrogenated amorphous silicon (a-Si:H), silicon germanium (a$\mathrm{SiGe}: \mathrm{H})$, and nanocrystalline or microcrystalline silicon $(\mathrm{nc}-\mathrm{Si}: \mathrm{H})$ or $(\mu \mathrm{c}-\mathrm{Si}: \mathrm{H})$ are one of the most important PV thin film technologies. [10,11]. The viability of such thin film photovoltaics has been 
demonstrated not only in the laboratory [12] but also in large-scale manufacturing [13] during the previous and actual decades. Amorphous silicon triple-junction solar cells, as for example a-Si:H/a$\mathrm{SiGe}: \mathrm{H} / \mathrm{a}-\mathrm{SiGe}: \mathrm{H}$ as presented by Yang and co-workers [10], supply open circuit voltages of up to 2.3 to $2.5 \mathrm{~V}$ as given in figure 3 .

Combining such a solar cell with a solar water splitting system integrating a PEM electrolyser may allow producing hydrogen during sunlight illumination of the solar cell. Moreover, if it would be possible to generate the necessary bias for the generation of hydrogen by the top tandem cell, the bottom cell may be used for the energy generation from the residual low-energy light that is not absorbed by the upper tandem cell. A schematic of the concept of the corresponding device including contacts and wiring is given in figure 2 .

The relatively simple layer-by-layer concept allows large-area module fabrication, makes the systems applicable to buildings, and exhibits strong cost-reduction potential as compared to similar concepts. No area atop the PEM electrolyser is lost, and a wide range of the sunlight spectrum $(\sim 350$ to $\sim 1100 \mathrm{~nm}$ ) is absorbed and converted. By this approach, electricity and hydrogen could be produced at the same time. By implementing the PV module in combination with the electrolyser in one compact system, it will be ideally suited for building applied photovoltaics (BIPV).

A possible system scheme, including hydrogen storage and a fuel cell to re-transform the hydrogen into electricity, is also shown in figure 2. Intelligent communication between generation system, inverter and energy storage may switch between maximum and minimum electricity generation. In case that the top tandem cell is not capable of splitting water efficiently, the whole triple junction may be used. In this case, still individual modules, one with the PEM electrolyzer to produce hydrogen and one without to produce energy, could be combined to a system that simultaneously generates solar electricity and hydrogen, and by that instantaneously deliver and store energy.

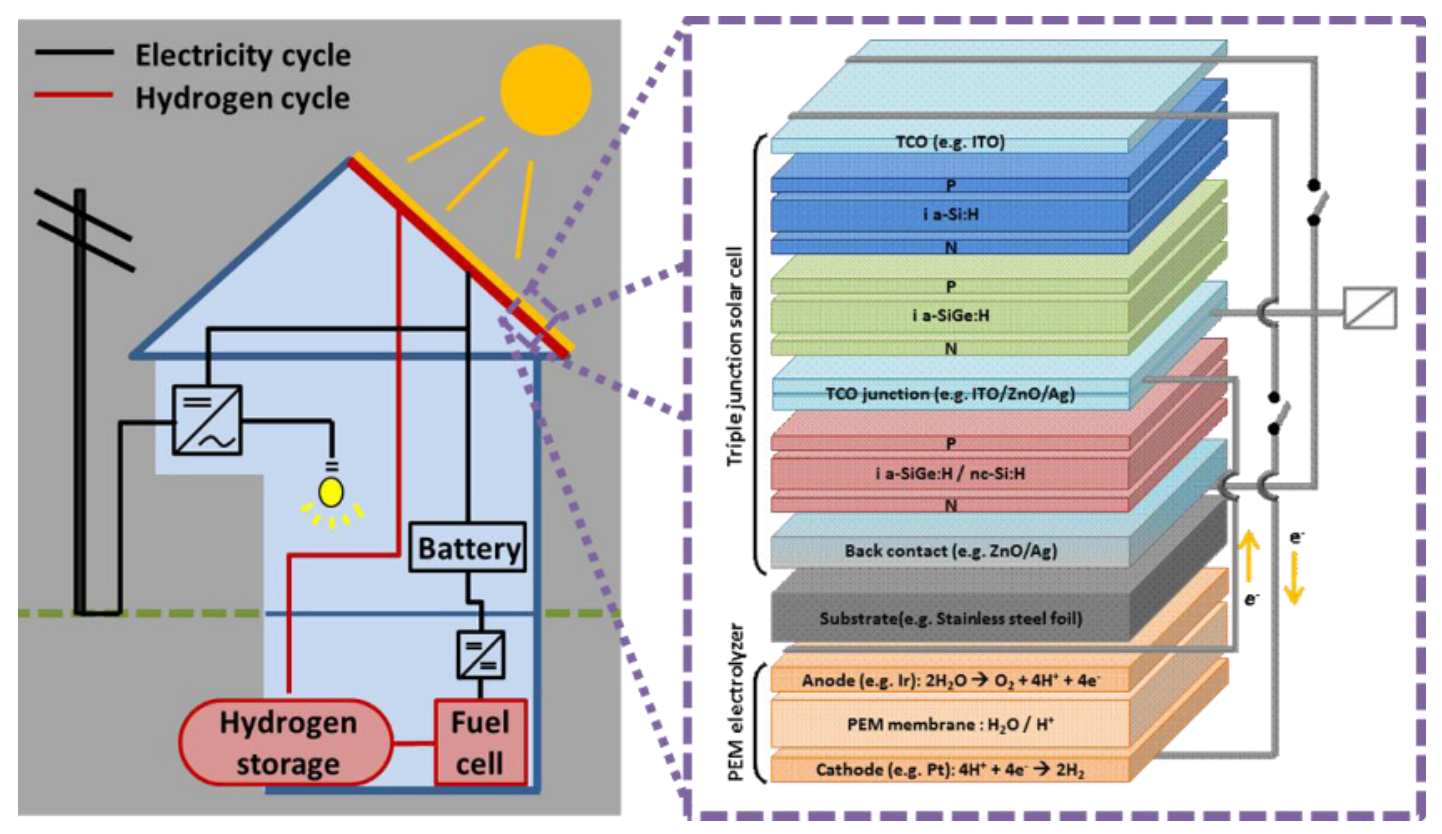

Fig. 2. System scheme of BIPV PV module/PEM electrolyzer system including hydrogen storage and a fuel cell, and electrical inverters (left image). Schematic of the presented concept for the simultaneous generation of solar electricity and hydrogen (right image): The current of the upper dual junction enables the water splitting reaction in the PEM electrolyser directly below the solar cell. Contacts, possible wiring, currents, and water dissociation reaction are shown schematically: The + and - contacts of the upper dual junction cell are directly connected to the PEM electrodes. 


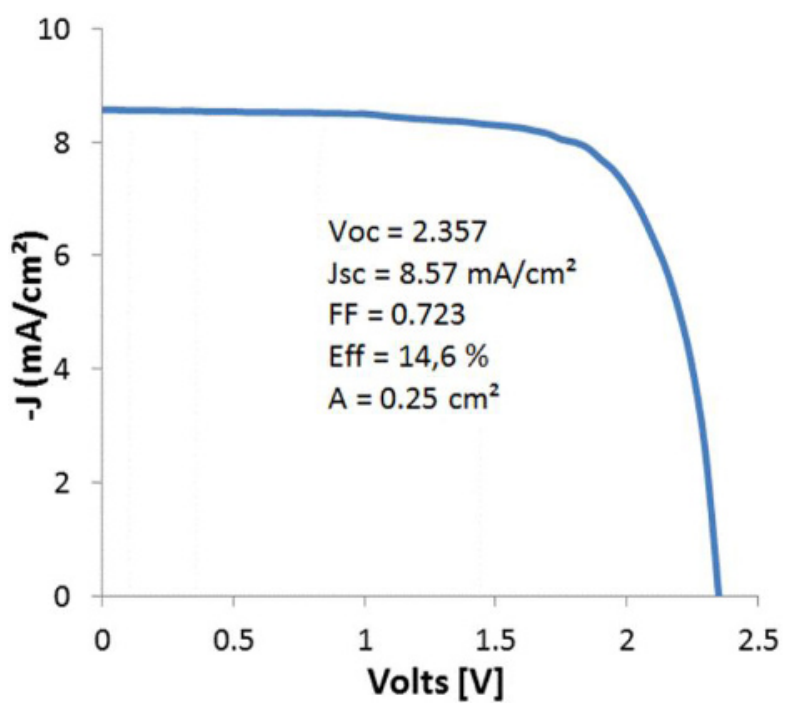

Fig. 3. Initial AM1.5 current-voltage (J-V) characteristics of triple-junction a-Si:H (a-Si:H/a-SiGe:H/a-SiGe:H) solar cell with $14.6 \%$ efficiency (adapted from [10]). Note: More recent cell records for the same technology reach up to $16 \%$.

\section{Evaluation of Concept}

The operating voltage $\left(\mathrm{V}_{\mathrm{op}}\right)$ of the cell as given in figure 3 can be easily set above the thermo-neutral voltage of $1.48 \mathrm{~V}$. The overall photoelectrolysis efficiency (excluding storage and utilization losses) can be obtained from:

$$
\begin{aligned}
& \eta_{\text {photoelectrolysis }}=\eta_{\text {photo }} \eta_{\text {electrolysis }} \\
& \eta_{\text {photoelectrolysis }}(T)=\frac{\eta_{\text {photo }} E_{H 2 O}(T)}{E_{O 2}(T)-E_{H 2}(T)} \\
& \eta_{\text {photoelectrolysis }}\left(25^{\circ} \mathrm{C}\right)=\frac{1.229 \mathrm{~V} \times \eta_{\text {photo }}}{V_{\mathrm{H} 2 \mathrm{O}}}
\end{aligned}
$$

In this case the system would reach a solar to hydrogen conversion efficiencies of $12.5 \%$, as can be derived from equation (3). According to information of the International Energy Agency (IEA) network [14], actually $40-60 \mathrm{kWh}$ of electricity is needed to produce $1 \mathrm{~kg}$ of hydrogen by a PEM electrolyser system.

Taking the aforementioned calculated expectable solar to hydrogen conversion efficiency of the proposed system into account, around $300-450 \mathrm{kWh}$ are needed to produced one $\mathrm{kg}$ of hydrogen. Assuming an actual system cost of around $3 € / \mathrm{W}$ for a $1-5 \mathrm{~kW}$ rooftop system in Germany [15], 1 $\mathrm{kWh}$ electricity from the PV system can be produced at around $0.15 €$ for a system lifetime of 25 years and a medium annual irradiation of $800 \mathrm{kWh} / \mathrm{kW}$. Hence, the resulting production price is in the range of $45-68 €$ per $\mathrm{kg}$ hydrogen. This is equivalent to 1.4 to $2.0 € / \mathrm{kWh}$, since $1 \mathrm{~kg}$ of hydrogen equates to $33.3 \mathrm{kWh}$.

Forecasting the historical trend line of the PV module experience curve to 2020, a mean module price of around $0.5 € / \mathrm{W}$ can be expected [16]. Accordingly, $1 \mathrm{kWh}$ will cost not more than $0.1 €$ in Germany and considerably less in Southern Europe. Assuming a moderate increase of the solar to hydrogen conversion efficiency of $2 \%, 250-375 \mathrm{kWh}$ will then be needed to produce $1 \mathrm{~kg}$ of hydrogen. Finally, this allows to produce hydrogen at $0.75-1.1 € / \mathrm{kWh}$. 


\section{Summary and conclusion}

A novel concept based on hydrogenated amorphous silicon (a-Si:H) triple-junction solar cells and a solar water splitting system integrating a PEM electrolyser is presented. Results show that it is possible to achieve a sufficient voltage of greater than $1.5 \mathrm{~V}$ for effective water splitting with a triple junction a-Si based solar cell.

The advantage of the proposed system lies in the possibility of energy production and storage at the same time and within one system, which may help to mitigate the 'Achilles' heel' of photovoltaics of non-uniform electricity generation. In addition, the relatively simple layer-by-layer concept allows large-area module fabrication, makes the systems applicable to buildings, and exhibits strong cost-reduction potential as compared to similar concepts.

Nevertheless, in case of grid-connection, the actual energy production cost for hydrogen storage by the proposed system is currently too high. In addition, modelling has to be done to clarify the applicability of a-Si based triple junction solar cells in terms of simultaneous generation of solar electricity and hydrogen. This could also answer the open question regarding possible overall system efficiencies, and whether it is more economical to operate a photovoltaic system that is based on cells/modules that simultaneously generate electrical energy and hydrogen or on cells/modules that generate either the one or the other. In both cases, intelligent communication between generation system, inverter and the energy storage component is required.

\section{References}

1. International Energy Agency, Technology Roadmap: Solar photovoltaic energy, http://www.iea.org/publications/free_new_Desc.asp?PUBS_ID=2260, (2010).

2. J.A. Turner, Science 285, p. 687-689, (1999).

3. G. Peharz, F. Dimroth, and U. Wittstadt, Int. Journal of Hydrogen Energy 32, p. 3248-3252, (2007).

4. J. Nowotny, C. C. Sorrell, L. R. Sheppard, and T. Bak, Int. J. Hydrogen Energy 30 p. 521-524, (2005).

5. A. J. Bard and M. A. Fox, Acc. Chem. Res. 28, p. 141-145, (1995).

6. S. Licht, Int. J. Hydrogen Energy 30, p. 459-470, (2004).

7. S. Licht, B. Wang, S. Mukerji, T. Soga, M. Umeno, and H. Tributsch, J. Phys. Chem. B 104, p. 8920-8924, (2000).

8. O. Khaselev, A. Banasal, and J. A. Turner, Int. J. Hydrogen Energy 26, p. 127-132, (2001).

9. O. Khaselev and J. A. Turner, Science 280, p. 425-427, (1998).

10. J. Yang, B. Yan, S. Guha, Thin Solid Films 487, p. 162-169, (2005).

11. A. V. Shah, , J. Meier, E. Vallat-Sauvain, N. Wyrsch, U. Kroll, C. Droz, and U. Graf, Sol. En. Mat. a. Solar Cells 78, p. 469-491, (2003).

12. J. Yang, A. Banerjee, and S. Guha, Appl. Phys. Lett. 70 2975, (1997).

13. S. Guha, J. Yang, A. Banerjee, T. Glatfelter, K. Hoffman, S.R. Ovshinsky, M. Izu, H.C. Ovshinsky, and X. Deng, Mater. Res. Soc. Symp. Proc. 336, 645, (1994).

14. International Energy Agency (IEA), IEA Energy Technology Essentials 05, Hydrogen Production \& Distribution, April (2007).

15. Internal market study, October (2011).

16. D. Swanson, Future Photovoltaics, December, (2011). 